\title{
EL LUGAR QUE OCUPA EL TRABAJO EN LOS JÓVENES MEXICANOS
}

\author{
Marco A. Leyva Piña y \\ Javier Rodríguez Lagunas
}

Resumen: En este texto, se pone el énfasis en una interrogante: ¿para los jóvenes mexicanos el trabajo es un referente básico en la organización de su vida en la sociedad? Esta interrogante resulta pertinente en el marco de las discusiones respecto al cuestionamiento del trabajo como eje de la construcción de las relaciones sociales. Con base en la Encuesta Nacional de Empleo Urbano y la Encuesta Nacional de la Juventud, se plantea la situación laboral de los jóvenes mexicanos, caracterizada por la precarización del empleo, y de la que podría suponerse un impacto poco relevante en la constitución de la identidad de ellos.

Palabras clave: sociedad, trabajo, empleo, jóvenes, precarización del empleo.

Marco Antonio Leyva Piña, candidato a doctor por la Universidad Autónoma Metropolitana, labora en Universidad Autónoma Metropolitana-Iztapalapa. Temas: educación, trabajo y jóvenes; sindicalismo, mercados de trabajo. Dirección: Universidad Autónoma Metropolitana Unidad Iztapalapa. Av. San Rafael Atlixco No. 186, Col. Vicentina Iztapalapa, C.P. 09340, teléfono y fax: 5804 47 70, correo electrónico: marcolp2000@yahoo.com.mx.

Javier Rodríguez Lagunas, candidato a doctor por la Universidad Nacional Autónoma de México, labora en Universidad Autónoma Metropolitana-Iztapalapa. Temas: educación, trabajo y jóvenes; sindicalismo, mercados de trabajo. Dirección: Universidad Autónoma Metropolitana Unidad Iztapalapa. Av. San Rafael Atlixco No. 186, Col. Vicentina Iztapalapa, C.P. 09340, teléfono y fax: 580447 70, correo electrónico: rolj@xanum.uam.mx.
Abstract: In this text, the emphasis in a question is put: for the Mexican young people the work is referring a basic one in the organization of its life in the society? This question is pertinent within the framework. from the discussions with respect to the question of the work like axis of the construction of the social relations. With base in the National of the Urban Employment Survey, the labor situation of the Mexican young people considers, characterized by the employment's precariousness, and of which a little excellent impact in the constitution of the identity from them.

Key words: society, work, employment, young people, employment's precariousness.

\section{Introducción}

$\mathrm{V}$ vimos hoy una fuerte disputa teórica con relación a la sociedad del trabajo. Por un lado, la idea de sociedad es con fuerza criticada e incluso se piensa que éste es un concepto inútil para entender a lo social en la actualidad; por otro, hay quienes han abonado esfuerzos desde hace tiempo para demostrar la existencia de la crisis del trabajo y por tanto de los actores e instituciones a los que dio nacimiento.

Dubet y Martuceli argumentan a favor de que la idea de sociedad haya sido un esfuerzo en la construcción de un objeto de estudio, una repre- 
sentación colectiva y una filosofía social para entender el orden social en un momento histórico caracterizado por el auge de la revolución industrial, de la revolución democrática y de la formación de los estados modernos. Para estos autores, la sociedad se pensó como un conjunto coherente organizado por algunos elementos fundamentales, diríamos nosotros, como el trabajo. Pero rechazan la concepción de sociedad como una totalidad organizada con un conjunto de funciones a desarrollar, porque es obsoleta para entender la complejidad y la diversidad de conductas sociales en la actualidad (Dubet y Martuceli, 1998).

Asimismo, la idea de trabajo se encuentra en un fuerte cuestionamiento. Se parte del hecho social de que el trabajo asalariado es el eje de la organización de la vida social en la sociedad industrial, al conformar las orientaciones básicas para la construcción de la socialización, vinculación e integración social, digamos de las relaciones sociales en su conjunto. Se piensa que el trabajo, al entrar en crisis, derivará en el estallido de las representaciones sociales, instituciones sociales y actores sociales que le son consustanciales (Offe, 1992 y Gorz, 1995).

Así pues, sociedad y trabajo se encuentran en fuerte cuestionamiento. Aún más, si juntamos ambos conceptos, en presunta crisis, en uno solo que sería la sociedad del trabajo, se podrán ampliar los ángulos de observación crítica que son muy diversos y dispares respecto al mismo. Hay discursos que se inclinan por la extinción inexorable de la centralidad del trabajo, otros mantienen cautela al reconocer que el trabajo, si bien ya no mantiene la hegemonía que tenía, continúa siendo un referente estimable en la construcción de la identidad de los actores laborales y algunos académicos argumentan a favor de la importancia que tiene el trabajo en la sociedad actual sin desconocer las transformaciones significativas en la producción y el trabajo que se generan con la ruptura del taylorismofordismo (De la Garza, 2000 y Neffa, 2004).
El reconocimiento de las limitaciones que presenta la idea de sociedad ordenada por un centro no ha conducido a la renuncia para la comprensión de lo social, como dicen Dubet y Martuceli (1998), a la construcción "de una imagen empírica y filosófica de los conjuntos en los cuales vivimos". De tal forma que la pregunta clave de la Sociología, de cómo se mantiene unida la sociedad, tiene vigencia aunque las respuestas clásicas se presenten hoy con dificultades para comprender las relaciones sociales actuales.

Asimismo, las críticas al concepto de trabajo y de su importancia en la sociedad han estado presentes desde el origen de la sociedad capitalista; sin embargo, lo interesante del debate actual es el presunto eclipse del trabajo como eje de la construcción de las relaciones sociales a tal grado que la interrogante de ¿trabajar para qué y en qué? adquiere una importancia crucial (Gorz, 1995). Al igual que en el debate de la vigencia del concepto de sociedad, el que se cuestione el trabajo no significa el eclipse del mismo ni en la teoría ni como proceso social de vital importancia en la comprensión de la sociedad. Desde la teoría hay un conjunto de observaciones que rechaza las críticas de la centralidad del trabajo, por ejemplo, por la confusión que existe entre lo que es el trabajo y lo que es el empleo asalariado, por limitarse a pensar que el trabajo posee un solo contenido y, para nuestro caso en particular, por la aplicación de modelos productivos con una fuerte carga eurocentrista que presentan dificultades para comprender mediaciones culturales y políticas articuladas al trabajo en los países latinoamericanos (ver por ejemplo a Suárez Zozaya, 2004 y Pérez Islas, 2001). Con relación a lo empírico hay mucha información para poner en duda la pérdida de relevancia de la industria en el desarrollo económico, de la emergencia de nuevos tipos y contenidos del trabajo que son asalariados, del ascenso de las luchas sindicales y de la vigencia del trabajo en la construcción de las identidades de los trabajadores (De la Garza, 2000). 
Ahora bien, en cuanto a los jóvenes existe literatura europea que coloca en duda la potencialidad del trabajo en la construcción de sus identidades. Por ejemplo, Gorz (1995) sostiene que la economía capitalista no está ya en condiciones de garantizar a cada uno y cada una su derecho al trabajo económicamente útil y remunerado, por lo que el trabajo asalariado deja de ser una fuente de identidad y de inserción social. Reitera que dicha situación afecta mucho la sensibilidad de los jóvenes que forjan como respuesta la aspiración a liberarse del trabajo como una forma de tomar el poder sobre sus propias vidas. Al contrario de esta observación, hay suficiente información teórica y empírica para sostener que el trabajo es un elemento central en la vida social de los jóvenes y que la precarización del empleo asalariado no conduce unívocamente a una pérdida del valor social del trabajo. El cuestionamiento a la tesis de debilitamiento o nulidad del trabajo en la constitución del sujeto joven que se realiza en los países europeos es un indicador que nos invita a la prudencia en la comprensión del comportamiento de los jóvenes (Sanchís, 1991). El influjo de las tesis de la posmodernidad que orientan a pensar sin unidades sociales, sin centros sociales, digamos sin totalidad social, así como la seducción de incorporar explicaciones con base en la existencia de nuevos modelos productivos trazados por la flexibilidad sin considerar las particularidades estructurales: de conflictos, luchas y cultura por las que atraviesa nuestro país en el que se encuentra la presencia de formas de organización del trabajo, como el taylorismo- fordismo, y de formas del trabajo muy típicas para nosotros pero muy atípicas para algunos países desarrollados, son moneda de circulación común en el análisis de la juventud y han generado la idea de la pérdida del valor social del trabajo en el comportamiento subjetivo, en especial en la construcción de la identidad de los jóvenes trabajadores (Suárez Zozaya, 2004 y Pérez Islas, 2001).
En este documento nos preguntamos si para los jóvenes mexicanos el trabajo es un referente básico en la organización de su vida en la sociedad, interrogante que tiene su pertinencia en el marco de discusiones respecto a la pérdida de centralidad de éste, que afecta el comportamiento de los jóvenes y de los adultos; asimismo, se plantea la situación laboral propia de nuestros jóvenes, caracterizada como de precarización del empleo, y de la que podría suponerse un impacto poco relevante para su constitución de identidad.

\section{Discusiones teóricas sobre la centralidad del trabajo}

En la sociedad actual el debate en torno al trabajo se convierte en un proceso complejo que pasa por la discusión de las dimensiones teóricas, empíricas y políticas. Vatin (2004) hace la precisión de que en la sociedad occidental se construyó un concepto de trabajo, que se convirtió en realidad social, sin equivalente en otras sociedades. Las discusiones respecto a la teoría y práctica del trabajo están presentes desde los orígenes de la sociedad capitalista. Vatin efectúa una revisión del contenido del trabajo que históricamente adquiere diferentes representaciones y sentidos, y encuentra asociaciones con el sufrimiento que viene desde Nietzsche, Freud, Bataille, Marcuse hasta Hannah Arendt, comprensiones como la del físico Charles Coulomb que lo mira como un producto, trabajo útil definido por el rendimiento, hasta comprensiones en las que el trabajo es acción, es acto mediante el cual el hombre se realiza para sí mismo y para los demás.

En la sociedad capitalista el trabajo es el eje principal para entender su organización y su producción cotidiana, la perspectiva marxista es una de las teorías relevantes en el análisis del trabajo y de su probable futuro en las sociedades. En esta óptica analítica, el trabajo asalariado se considera como trabajo enajenado 
que tendrá que desaparecer por medio de movimientos revolucionarios, para dar paso a la constitución de la sociedad socialista y, posteriormente, comunista en las que el trabajo sería una condición para la libertad y la realización de la persona.

Así, estamos ante concepciones que perciben el trabajo de diferente forma y éste no es un ejercicio neutral ya que cada una de ellas prefigura un posible futuro. En consonancia con el entendimiento conceptual del trabajo, también desempeñan un rol fundamental los procesos políticos y sociales que acontecen en la sociedad, como el derrumbe de los países socialistas, el desarrollo de la globalización y del neoliberalismo, la aparición de nuevas formas de trabajo y de producción, la importancia que adquiere el sector terciario y la aparición de un cuarto sector en la producción ligado a las nuevas tecnologías, y la constitución de nuevos sujetos laborales con sus propias cargas emocionales y sentimentales.

En este contexto, de fuerte polémica en torno a la concepción del trabajo, uno de los discursos que ha adquirido relevancia a nivel internacional es aquel que se refiere al "fin de la sociedad del trabajo". Las propuestas que se hacen desde estos análisis, para los países desarrollados, se han intentado hacer extensivas a otras realidades como las de las sociedades subdesarrolladas o en proceso de desarrollo como la nuestra. Si bien se reconoce que estamos en una época de globalización, hay particularidades significativas que son de difícil aprehensión en esos discursos apocalípticos del trabajo.

Enrique De la Garza (1998) realiza una síntesis de las principales tesis del fin de la sociedad del trabajo que a continuación se presentan:

Tesis 1.- Incremento de la heterogeneidad de los trabajadores con implicaciones en sus normas, valores y actitudes derivada de la declinación de la industria y del repunte de los servicios. Este cambio sensible de la estructura productiva trae como consecuencia la modificación de las ocupaciones que se observa a través del crecimiento relativo de trabajadores calificados, ingenieros, técnicos, empleados de cuello blanco, y la aparición de una serie de trabajos atípicos como temporales, por hora, a tiempo parcial.

Tesis 2.- El trabajo pierde centralidad en la constitución de identidades colectivas por la fragmentación de los mundos de vida. En este sentido, el autor apunta que la pérdida de centralidad del trabajo es en el conjunto de las relaciones sociales capitalistas.

Tesis 3.- La disminución del peso político del trabajo en la sociedad actual se relaciona con su función de generador de valor.

Tesis 4.- Desde la década de los ochenta, la clase obrera y las organizaciones sindicales fueron derrotadas y esto influyó en la crisis del trabajo.

Por su parte, Julio César Neffa (2004) hace un repaso abundante de los diversos planteamientos del fin de la sociedad del trabajo entre los que destaca el de Jean Marie Harrybey al presentar una agrupación creativa de las posiciones respecto al tema. Según Harrybey, hay quienes conciben el fin de la sociedad del trabajo como algo inevitable, mientras que otros piensan que el trabajo asalariado no ha finalizado. En el primer grupo hay dos posiciones: unos que se inclinan a pensar que es positiva la declinación de la sociedad asalariada y otros que perciben dicho fenómeno como algo lamentable. En la posición positiva coloca a André Gorz quien ha argumentado, desde la década de los setenta, la tendencia irreversible de la crisis de la sociedad del trabajo y ha supuesto que esta extinción efectiva permitirá la aparición de una economía más plural, expandiendo las actividades humanas dentro de la esfera mercantil, asegurando a todas las personas un ingreso de existencia que no implicaría, en contrapartida, más trabajo. En la posición negativa, Harrybey sitúa a $\mathrm{J}$. Rifkin para quien el fin de la sociedad del trabajo es un hecho irreversible por los efectos de la globalización y de la incorporación de novedosas tecnologías de la 
información y de las comunicaciones que generan incrementos de la productividad y que condenan al desempleo a la mayor parte de la población.

En el agrupamiento de los defensores de la sociedad del trabajo, que en principio dudan de que el trabajo asalariado vaya a desaparecer a corto o mediano plazo, Harrybey los clasifica en dos tipos: por un lado, están los que afirman que el modo de producción capitalista puede evolucionar hacia la satisfacción de las necesidades de las personas por medio del desarrollo de las actividades mercantiles, adoptando modalidades productivas y de gestión de la fuerza de trabajo flexibles, como reducir costos de producción, aprovechar los beneficios que ofrecería la mundialización, desarrollar el comercio y la competitividad. Por otro lado, están los que afirman que la centralidad del trabajo se puede mantener siempre y cuando se realicen transformaciones radicales entre el capital y el trabajo. En este punto, tanto socialdemócratas como comunistas apuestan al crecimiento económico como una cuestión básica para pensar en la posibilidad de que el trabajo podrá tener continuidad en la sociedad del presente (Harrybey, 2001, tomado de Neffa, 2004).

En la discusión del fin de la sociedad del trabajo hay una interesante variedad de posiciones teóricas a favor y en contra, con posturas metodológicas diferenciadas que orientan a la construcción de datos empíricos bastante contrapuestos y a inclinaciones políticas discrepantes. Los estados del arte respecto al fin de la sociedad del trabajo hechos por De La Garza (2000) y Neffa (2004), como hemos visto, resumen las principales tesis internacionales que tienden a incrementarse pues el debate, lejos de agotarse, reaparece con intensidad mostrando sugerencias teóricas y datos empíricos necesarios de consideración.

Dubet y Martuceli, al analizar en Francia las transformaciones del trabajo y la producción, argumentan que se rompieron los equilibrios económicos y sociales instalados desde la segunda guerra mundial, dando cauce a la aparición de una variedad de combinaciones entre la organización taylorista-fordista y los nuevos procedimientos de racionalización industrial, tipificados como flexibles. Para ellos, la estructura de producción en Francia se transformó de forma considerable desde la mitad de los años setenta: el sector servicio se hizo extensivo en comparación con la contracción del sector industrial y primario, pese a ello reconocen que las actividades industriales siguen siendo los sectores claves de creación de la riqueza (Dubet y Martuceli, 1998: 142).

En ese país europeo, según estos autores, existe una flexibilidad del conjunto de la organización productiva que se expresa en la segmentación del mercado de trabajo, la precarización del empleo y en la fragmentación de los estatus laborales. La flexibilidad del trabajo se refleja en "tasa de desocupación elevada para los trabajadores no calificados, desocupación femenina alta, gran desocupación de los jóvenes activos y una importante desocupación de larga duración" que no disminuyó pese al repunte económico de fines de los años ochenta. Asimismo, la precarización del empleo afecta a los jóvenes: "en 1997, el 41\% de los jóvenes tiene un contrato con una duración determinada; en 1993, 70\% de los jóvenes tiene su primera experiencia de vida activa en los empleados precarios" (Dubet y Martuceli, 1998:142-44).

La flexibilidad del trabajo y la producción y sus efectos negativos en la clase trabajadora carecen de asidero claro para las tesis del rechazo de la centralidad del trabajo en ese país. Los autores que comentamos mantienen una posición de cautela respecto a la relación trabajo e identidad al señalar que "el trabajo sigue siendo un lugar privilegiado de construcción de una de las representaciones dominantes del sujeto de nuestra sociedad, pero ya no tiene el rol hegemónico con el cual se beneficiaba antaño" (Dubet y Martuceli, 1998: 148). Estos autores se mantienen en una encrucijada, ya que por un lado sostienen que el trabajo deja de ser el 
referente exclusivo en la integración social, en la organización de la sociedad y en la constitución de significaciones $\mathrm{y}$ valores, $\mathrm{y}$ por otro lado, no se deciden a restarle importancia, de tal forma que el trabajo es y no es al mismo tiempo fuente de identificación. Esta opción es poco convincente al titubear en proponer quién ocupará el lugar que deja el trabajo y por ello se limitan a suponer que en lugar de ese centro aparece una pluralidad de lugares de identificación, todos con la misma influencia, aparentemente.

Esta transición de la centralidad del trabajo a otra posición en la que ocupa un lugar sólo de privilegio, condición que comparte, sin saberse con claridad su relación, con otras dimensiones de la realidad, permite la aparición de sugerencias como ésta: "La significación subjetiva del trabajo difiere según la posición del individuo en lo alto o en lo bajo de la jerarquía profesional. Es arriba de la misma que se colocan en primer lugar las dimensiones expresivas del trabajo, mientras que las categorías sociales colocadas en el nivel más bajo de la jerarquía tienen tendencia a acentuar las dimensiones instrumentales del mismo" (Dubet y Martuceli, 1998: 149).

Se puede derivar de la anterior sugerencia teórica que la mayoría de la población que se sitúa en general por abajo de la jerarquía profesional viviría el trabajo como una obligación y buscaría espacios fuera de él para desarrollarse como individuos. En contraparte, las minorías gozarían de un trabajo que les permitiría su realización personal y social. Esta dicotomía presupone que la clase obrera fue un conjunto homogéneo con una identidad similar y compartida que se desgaja hoy día por los procesos de transformación del trabajo y de la producción, para dar paso a una heterogeneidad estructural laboral, por lo menos dos bloques diferenciados de trabajadores que enfrentan situaciones laborales distintas con su propia generación de identidad. Presupuesto que ya ha sido criticado pues en el pasado la clase obrera no fue tan homogénea como se pensaba (De la Garza, 1998).
Criticar las teorías tradicionales de la sociedad es un esfuerzo interesante de creación de conocimiento social; sin embargo, aún no aparecen planteamientos teóricos consistentes como los criticados, pues lo nuevo en la teoría presenta dificultades fuertes como lo expuesto por Dubet y Martuceli cuando realizan la separación entre lo instrumental y lo expresivo para entender la subjetividad que emerge de un trabajo fragmentado como el que prevalece en la actualidad. Estas sugerencias presentan debilidades conceptuales más fuertes de las que intentan corregir, ya que pueden existir situaciones en las que se manifiesten, en un mismo agregado de trabajadores o de actores sociales, tanto la racionalidad expresiva y la instrumental, como es el caso de los jóvenes mexicanos.

A la par de las tesis del fin de la sociedad del trabajo aparece una serie de respuestas que pone en evidencia teórica y metodológica esas propuestas. Como bien lo mencionan Dubet y Martuceli, la expansión de los servicios no ha significado una pérdida importante de la industria en la generación de la riqueza. También de La Garza señala que la caída de la ocupación industrial es en Europa y en Estados Unidos, en cambio en los países del sudeste asiático se dan otras tendencias, así como en Canadá y en América Latina, lo cual no deja de mostrar el carácter eurocentrista en muchas de las consideraciones sobre el futuro del trabajo (De la Garza, 2000). Hayman (1996), por su parte, cuestiona la idea de la existencia de una edad de oro del sindicalismo en términos de unidad y homogeneidad en los estados fordistas y en su lugar sostiene que la clase obrera siempre ha sido heterogénea, aunque dicha situación adquiere sus particularidades según el momento histórico.

Como la pretensión de este trabajo no es la exposición de todas las críticas a las tesis del fin de la sociedad del trabajo, se consideran las expuestas como indicativas de las debilidades de esas propuestas para explicar la crisis del trabajo en términos de centralidad, 
lo que sugiere por lo menos precaución en su aplicación para los países de América Latina en donde la situación laboral pasa por cortes históricos y procesos sociopolíticos específicos que la dotan de singularidades que deben tenerse en cuenta.

Si las narrativas de la crisis del trabajo, que inevitablemente presagian la extinción de la sociedad industrial, se han recibido con una actitud crítica, igual suerte han corrido aquellos planteamientos que sostienen que las normas, valores y actitudes de los jóvenes ya no están constituidos por el trabajo. Hay que señalar que las narrativas de las nuevas identidades juveniles, como formas de constitución de subjetividad, tienen un fuerte anclaje en la idea de la desaparición del trabajo como eje de las sociedades actuales. Sin desconocer la fuerza de las transformaciones significativas del trabajo y de la producción, que presenta particularidades importantes según los países y ramas productivas, consideramos que son aún apresurados esos diagnósticos que en teoría impresionan pero carecen de evidencias empíricas sólidas y más para nuestro país. ${ }^{1}$

Sanchís (1991:82) realiza una exposición crítica y muy completa de las propuestas de los valores y actitudes de los jóvenes (poniendo énfasis en la dimensión política) respecto al trabajo en Europa. Sostiene que es peligroso mirar el problema de la desocupación sólo desde el lado de la oferta pues serían los propios jóvenes quienes - con su elevada exigencia de empleo, rechazo de la disciplina laboral y escasa motivación hacia el trabajo- se autoexcluyen del empleo. En las literaturas española, italiana y francesa, los postulados conceptuales que atribuyen a los jóvenes actitudes de rechazo al trabajo, muestran con ironía creencias populares como la de que: "los jóvenes no tienen ganas de trabajar" y sostienen que es falsa la tesis de que los jóvenes actuales rechacen el trabajo y que el mecanismo de socialización por medio del trabajo se haya roto. Asimismo, reconocen que si la crítica se fundamenta en términos de que "el trabajo ha dejado de ser un valor central y cada vez es contemplado sobre todo en sus aspectos instrumentales, es decir, como medio para conseguir otras cosas, entonces la cuestión se complica bastante, pues datos empíricos y diversas líneas interpretativas llevan a conclusiones no convergentes" (Sanchís, 1991: 83-84).

El autor comentado señala críticas metodológicas interesantes que hasta el momento consideramos no se han resuelto, por ejemplo: ¿con quién comparar a los jóvenes, con los de la generación anterior, con los coetáneos adultos, con un antes idilico en el que había conciencia profesional, esperanza en la promoción, amor al trabajo y satisfacción en la obra bien hecha?

Por la importancia que tiene para este documento la interesante discusión de la centralidad del trabajo en los jóvenes realizada por Sanchís, a continuación se presentará una síntesis de la misma. Para Cuvillier (1974) el trabajo es una obligación desagradable producto de la nula participación del trabajador en su diseño, lo que lo convierte en fuente de tedio y de su empobrecimiento como ser humano. Al negar su dimensión expresiva aflora como un mal necesario para ganarse la vida del que se excluye todo placer y potencial de realización personal y social. De esta observación Sanchís sugiere que los valores que se supone deberían gobernar las actitudes de los jóvenes frente al trabajo nunca fueron demasiado centrales.

Asimismo, Cottereau (1979) señala que en el capitalismo industrial, tanto para las muchachas como para los muchachos, el trabajo obrero nunca fue contemplado como un fin en sí mismo capaz de definir las esperanzas de la mayoría. Hace una diferencia entre la obligación al trabajo asalariado y la adhesión ideológica a éste. Discrepancia que conduce a la tesis de que la descalificación del trabajo al extenderse deriva en una concepción instrumental, que no significa rechazarlo o boicotearlo (Sanchís, 1991: 87).

Desde una posición escéptica, Romagnoli (1984) parte de la dificultad de encontrar una demostración 
convincente de la centralidad del trabajo para los adultos, de la cual deriva la sospecha de que mucho de lo que se ha dicho sobre la crisis del trabajo tiene una gran carga ideológica. Este autor pone en entredicho las opiniones de aquellos que afirman que los jóvenes empiezan a manifestar una relación diferente respecto al trabajo, pues habría que preguntarles ¿diferente respecto a qué, al orgullo de un oficio que ya no existe o al instrumentalismo de las sociedades opulentas? No hay respuestas convincentes a estas diferencias, sin embargo, la actitud de los jóvenes hacia el trabajo asalariado podría ser su rechazo masivo, lo que no es una novedad, pero contra el trabajo no se ha producido nada de este tipo.

De los anteriores planteamientos, es necesario considerar algunas advertencias como la inexistencia de un grupo juvenil cuya ideología contenga el rechazo al trabajo para diferenciarse respecto al adulto, y la involución del trabajo de una concepción centrada en el valor a otra que lo percibe como un mero instrumento para obtener cosas.

Accornero (1980) confirma que los jóvenes no rechazan el trabajo, ni como prejuicio ni como comportamiento (Sanchís, 1991: 89). Esta posición se refuerza en el informe de Schwartz (1982) al incorporar una sutileza que es necesario tener presente: los jóvenes no rechazan el trabajo, lo desmitifican; el supuesto es que el trabajo descalificado ya no permite la realización personal de los jóvenes, al desvincular la producción del sistema de valores. Tal situación lleva a que los jóvenes cuestionen los modelos jerárquicos tradicionales y la parcelación de las tareas, y en su lugar reivindican más autonomía en la organización del trabajo y a su vez, aunque parezca ambiguo, reconocen en el trabajo un sentido de utilidad.

En España, Moncada (1979) reconoce que los jóvenes tienen una imagen idealizada del trabajo, sin embargo, se conformarían con cualquier tipo de trabajo. Advierte que es un error común afirmar que la juventud no desea trabajar, sino divertirse. De esta apreciación Sanchís reitera que ninguna investigación empírica española ha detectado la existencia de actitudes u opiniones de rechazo cuantitativamente relevantes.

La OCDE (1984) coincide con los planteamientos anteriores al constatar que carecen de fundamento los temores de que la ética del trabajo sea rechazada por los jóvenes, más bien éstos tienen una actitud crítica frente al trabajo y se encuentran preparados para adaptarse al mismo. Este organismo internacional no encuentra diferencias sustanciales entre los jóvenes y los adultos ya que ambos se acomodan al empleo que tienen.

Capecchi (1980) concluye que hay un elevado porcentaje de jóvenes que, de una u otra manera, combina el estudio con el trabajo. Además, observa la tendencia de que los jóvenes abandonan los estudios cuando se les presentan oportunidades de empleo, lo cual pone en aprietos la tesis del rechazo del trabajo (Sanchís, 1991: 94).

Blanch (1986), apoyándose en resultados de una investigación realizada en diferentes países, expone que en las sociedades occidentales el trabajo sigue percibiéndose como un valor central en la conformación de creencias y actitudes, y por lo tanto en la construcción de identidades. Tanta es la influencia del trabajo en los valores de los jóvenes que recomienda luchar contra esa hegemonía como una forma de terapia preventiva de salud mental.

Desde estudios de satisfacción laboral realizados en jóvenes ocupados, se coloca en aprietos las tesis de rechazo al trabajo. Galland, Romagnoli (1984) y García Ferrando (1984) manifiestan que los jóvenes en su mayoría se encuentran satisfechos con su trabajo, a pesar de las duras y malas condiciones de éste. Sanchís reinterpreta lo anterior en el sentido de que los jóvenes, más que satisfechos con el trabajo, se consideran con la suerte de encontrar un espacio en el mercado de trabajo. En consecuencia, trabajar tiene aceptación en 
los jóvenes, lo que cuestionan es el tipo de trabajo y cómo se hace (1991: 101).

Neffa (2004) realiza una síntesis de las tesis que promueve el Centre des Jeunes Dirigeants de Francia y resalta lo siguiente: "el pleno empleo nos ha hecho olvidar que el empleo asalariado no debe ser el único vector de la actividad social, ni la empresa el único lugar de socialización". Crítica que se basa en la diferencia entre trabajo y empleo asalariado; al primero se le concibe como fuente de realización personal, de relación social y de subsistencia para el hombre, mientras se sugiere que el segundo sea abolido. Esta agrupación juvenil propone la desaparición de la influencia que tiene la empresa en la vida de los hombres por sus resultados como la generación de desempleo y de exclusión. La renuncia a la sociedad-empresa y en su lugar la constitución de una sociedad multiactiva reivindicará el valor del trabajo al margen del empleo asalariado.

El fin de la centralidad del trabajo en la constitución de la sociedad actual y la venidera se enfrenta a cuestionamientos de envergadura en las sociedades europeas y norteamericana, y el intento de hacerlos extensivos a los países en desarrollo se vuelve muy problemático ya que significa obviar la historia de este continente y la multiplicidad de procesos políticos culturales y de lucha que contextualizan la formación de subjetividad y de identidades. Es cierto que se vive en un mundo globalizado pero eso no implica la desaparición de desigualdades entre los países, al contrario, se han conformado nuevas asimetrías que exigen mantener en el análisis las diferencias históricas y presentes del trabajo y la producción que son específicas para nuestros países. De tal manera que el desempleo en las sociedades desarrolladas y subdesarrolladas, como las de América Latina, tiene diferencias en cuanto a sus causas, sentidos y posibles soluciones (Pries, 1992).

En la literatura expuesta se resalta la inclinación a mantener la concepción de que el trabajo continúa siendo un elemento importante en la vida de los jóvenes. Al contrario de concepciones comunes se refuerza la idea de que, en lugar de rechazarlo, le conceden un valor alto; los motivos de esta elección, sus probables sentidos y derivaciones políticas son los temas que se encuentran en discusión, ésta es una situación problemática a la que también se enfrentan los adultos. El examen de la centralidad o no del trabajo en la vida social es un tema abierto y en debate, pero como sostiene Sanchís hay que tener una actitud de alerta a las derivaciones políticas de cualquiera de los planteamientos que se realicen, como en el caso de la afirmación de que son los propios jóvenes quienes se autocondenan al paro a causa de los valores y actitudes que mantienen ante el trabajo, que de paso es necesario señalar su debilidad en cuanto a datos empíricos.

\section{Precarización del empleo de los jóvenes}

La situación económico-política imperante en el país, resultado de la aplicación de políticas económicas, laborales y productivas de carácter neoliberal, combinadas con el achicamiento del Estado, ha impactado de manera negativa la seguridad social y ha traído como consecuencia la degradación del trabajo que tiene una de sus expresiones en la precarización de los empleos. Así tenemos que en el período 2000-2004 la desocupación abierta tuvo un crecimiento poco significativo, pues representó menos de un punto porcentual, situación similar mostró la generación de empleos al aproximarse al uno por ciento. ${ }^{2}$ Los sectores primarios y secundarios, en términos generales, tuvieron un retroceso, a diferencia del terciario, que en sus distintas ramas creció de manera significativa. ${ }^{3}$

El comportamiento del empleo presenta diferencias por sexo a tal grado que se tiende a hablar de una feminización de la fuerza de trabajo. El empleo entre hombres y mujeres disminuyó en cuanto a la 
proporción de trabajo asalariado. Este proceso caracterizado como de asalariamiento de las mujeres, se ubica con predominio en los sectores de la manufactura y los servicios, lo que no significa un abatimiento de las desigualdades de género. ${ }^{4}$

Los índices de bajo desempleo pueden ser satisfactorios para las autoridades laborales, pese a las deficiencias que existen en la metodología para medirlos, pero para las mayorías su suerte es de preocupación ya que el mercado de trabajo funciona con ineficiencia si tomamos en cuenta que los empleos que se ofrecen son empleos precarios, con salarios desvalorizados y condiciones de trabajo decrecientes.

El crecimiento del sector servicios y de algunas ramas del sector secundario ha generado empleos en las microempresas en donde los trabajadores tienen jornadas de trabajo reducidas o demasiado extensas respecto al promedio, se encuentran sin pago salarial o con mínimas remuneraciones y sin acceso a la seguridad social (Salas y Zepeda, 2003: 56).

De la Garza ofrece información que fortalece el aspecto anterior de degradación del trabajo al señalar lo insuficiente del salario mínimo actual para sostener el nivel que se tenía en 1993, porque éste sufrió una caída real de $33.3 \%$ entre el 2000 y el 2005 y sólo creció 4.3\% en el mismo período (De la Garza, 2006).

Además, en ese período del análisis, el $44 \%$ de los trabajadores asalariados no tiene contrato escrito, el $41.6 \%$ no cuenta con prestaciones; además, desciende el porcentaje de trabajadores que cuenta con prestaciones de salud (pasó del $60.9 \%$ al $57.9 \%$ ), y gran parte de la población trabajadora no tiene contrato escrito ni cuenta con estas prestaciones.

En términos generales, las condiciones laborales de los trabajadores son difíciles, o mejor dicho, angustiantes. Todo indica que nos tenemos que acostumbrar a la generación de empleos precarios y a salarios que no cumplen los mínimos requisitos para una reproducción social adecuada de los trabajadores. La reestructuración de la actividad productiva y la desregulación de los mercados de trabajo para buscar mayor competitividad internacional llevan a la incertidumbre y pérdida de los derechos laborales. Aun así, es temerario sostener que el trabajo dejó de constituir un referente básico en la construcción de la subjetividad de los trabajadores (De la Garza, 1998).

En el contexto laboral presente, de acuerdo con la Encuesta Nacional de Empleo, la juventud mexicana que pese a los niveles de desempleo ${ }^{5}$ se vincula al mercado de trabajo, por lo menos al momento de aplicarse dicha encuesta, es la siguiente: el $43.9 \%$ de los jóvenes sólo trabaja y un $16.1 \%$ trabaja y estudia, pero si sumamos ambos porcentajes tenemos que un $60 \%$ de los jóvenes mexicanos se encuentra vinculado a alguna actividad económica. Con independencia de las razones que ellos tengan para trabajar, se puede observar que la necesidad de tener un empleo es una característica vital de la población juvenil mexicana: siete de cada diez jóvenes ha tenido una experiencia laboral.

En los jóvenes mexicanos el trabajo es una forma de vinculación con el mundo social, además de que una parte significativa de ellos tiene contacto con alguna actividad económica; se unen desde edades muy tempranas al mercado de trabajo; más del $90 \%$ tiene sus primeras experiencias laborales desde los 11 años, pero también tiende a combinar el trabajo con los estudios. De los encuestados, $54.6 \%$ se encontraba estudiando cuando comenzó a trabajar y la cifra crece en las poblaciones más jóvenes y se reduce en las más adultas.

Para los jóvenes, tener una escolaridad se convierte en una condición favorable para su inserción en el mercado de trabajo. La percepción de un grupo considerable de jóvenes es de que la escuela es un mecanismo que les permitirá alcanzar un empleo bien remunerado, incluso el $68 \%$ de ellos, que por alguna razón abandonó sus estudios, desea retornar a la escuela para aprender algo más y, sobre todo, para obtener un mayor ingreso. 
Cuando tienen concluidos sus estudios a nivel primaria aumentan sus posibilidades en comparación con aquellos que no tienen estudios, y dicha situación se mantiene en 1.8 veces de encontrar un empleo con relación a los que han logrado obtener el nivel de secundaria. Lo contrario ocurre cuando se ha concluido el nivel medio superior, pues la presencia juvenil decrece en el mercado y puede entenderse porque los jóvenes, cuando tienen mayor posibilidad de continuar estudiando, retrasan su inserción en el mercado laboral por su permanencia en la escuela. A las mujeres les acontece similar situación que a los hombres, porque si no cuentan con ninguna instrucción se les impide obtener un empleo en un 0.5 en comparación con tener secundaria. Con nivel de preparatoria la probabilidad de entrar aumenta 1.2 veces más que si sólo hubieran terminado la secundaria.

El aumento en el nivel de escolaridad y en la tasa de desempleo en la población de 15 a 29 años coloca en tela de juicio el imaginario tradicional que señala que después de la educación formal siguen la posibilidad de empleo, autonomía económica y participación social y económica (De Oliveira, 2006).

Los jóvenes se constituyen en diversos grupos sociales o estratos que presentan diferencias y desigualdades entre ellos; los que se encuentran en una escala social más alta cuentan con mayores posibilidades para beneficiarse de las condiciones institucionales que ofrecen la escuela y el trabajo. Éste es un hecho social de impacto diverso en los sectores juveniles en cuanto a sus expectativas y logros en lo laboral y escolar, en parte porque están sujetos a la oferta y demanda de los mercados laborales y por sus formas de vinculación con redes sociales que poseen capital social y cultural (De Oliveira, 2006).

Los jóvenes que tienen el privilegio de terminar sus estudios de licenciatura prolongan el tiempo para emplearse: el $25.1 \%$ tarda un año, el $15 \%$ dos años, el $23.2 \%$ cuatro años y el $9.2 \%$ tres años, diferencias que pueden obedecer a las exigencias profesionales de los egresados que se enfrentan a un mercado laboral precario. Además, el hecho de que el $40 \%$ de jóvenes se integre con cierta prontitud a un empleo no indica como necesaria una dinámica atractiva de los mercados de trabajo, incluso se puede advertir un acceso a cualquier empleo (muchas de las veces precario) en la medida en que es mejor tener un ingreso a esperar cubrir las exigencias de un mercado de trabajo que, por un lado, demanda preparación teórica y conocimiento práctico y, por otro, ofrece inestabilidad e inseguridad laboral (Sanchís, 1991).

La precarización del empleo que se logra vislumbrar para los jóvenes que tienen una profesión se hace más delicada para los de estratos más pobres, quienes optan por cualquier tipo de trabajo y postergan, retrasan o desertan del sistema educativo y, por lo tanto, sus expectativas de vida son limitadas y la oportunidad para su reproducción social se reduce significativamente (Navarrete López, 2006).

La inserción en el mercado de trabajo por parte de los jóvenes puede ser diferenciada en el interior de la población juvenil. Para un sector de jóvenes se observan tiempos de desempleo cortos y también reducidos para encontrar trabajo; el $73.8 \%$ ha buscado y encontrado trabajo entre uno y tres meses, $9.6 \%$ tarda de cuatro a seis meses y el $4.3 \%$ tarda siete meses o más. La rápida inserción obedece a que estos jóvenes se incorporan a trabajos informales mal remunerados, al carecer de experiencia laboral y de calificación profesional. Esta situación probablemente no se modificará para muchos, pues la degradación del trabajo como condición estructural del empleo en poco se modifica con la llegada a la edad adulta.

La información proporcionada por la encuesta permite poner en duda las tendencias del pasado en cuanto a la inserción laboral de los jóvenes. Actualmente, hay una idea común de la existencia de una 
moratoria social de los jóvenes en su incorporación a la estructura del empleo; por ejemplo, para los jóvenes españoles su inserción al empleo se calificaba como de rápida y segura en la época del Estado de Bienestar en comparación con la del neoliberalismo que se concibe como lenta, difícil e incierta (Prieto, 1999).

En México, los jóvenes tienden al empleo precario más que en otras poblaciones de trabajadores; además, se puede observar un proceso con matices significativos diferentes al caso español; la experiencia laboral desde temprana edad de los jóvenes mexicanos, en la actualidad, al menos por los resultados de la encuesta, nos indica una inserción rápida pero con altos niveles de inseguridad laboral, lo cual cuestiona la presunta moratoria social de ellos, y nos sugiere que el trabajo para los jóvenes mexicanos sigue siendo el parámetro de integración social y de inserción en la vida adulta

Por otro lado, las actividades económicas, considerando el primer empleo, que más absorben fuerza de trabajo juvenil son las relacionadas con el comercio, empleados y agentes de venta que conforman el 21.4 $\%$; luego vienen las actividades agrícolas y ganaderas con el $14.9 \%$; le siguen los ayudantes, peones y similares con el $12.2 \%$; los servicios domésticos con el $10.8 \%$ y, finalmente, los servicios personales con un $9.5 \%$ de participación. Es notorio que en actividades relacionadas con el trabajo industrial es poco significativa la presencia de los jóvenes, pese a que el 14.7\% inicia su primer empleo en la manufactura. Si consideramos, ahora, el último empleo tenido, estas proporciones son similares a las comentadas. De los encuestados, son pocos los que tienen relación con actividades profesionales: $2.8 \%$ de técnicos, $4.4 \%$ como operadores de maquinaria fija y $1.9 \%$ como trabajadores de la educación (Instituto Nacional de la Juventud e INEGI, 2001).

Los jóvenes se insertan en uno de los sectores que se conciben como el futuro del desarrollo de los países o por lo menos como el inevitable: el terciario. Sin embargo, y a diferencia de lo que ocurre en los países desarrollados, en México este sector se caracteriza por su bajo nivel tecnológico y por condiciones laborales y de seguridad social precarias que dejan mucho que desear para el futuro laboral de los jóvenes y sugieren muchas dudas en cuanto a una modernización económica y productiva que pueda ser equiparable con los países desarrollados.

Con relación al salario, según la Encuesta Nacional de la Juventud (ENJ), el 45.8\% manifestó ganar menos de 1500 pesos mensuales en su último empleo, $34 \%$ entre 1500 y 3999 pesos y un $8.7 \%$ se ubicaba entre 4000 y 7000. Así, ocho de cada diez jóvenes gana hasta 4000 pesos mensuales. En general, parece que la tendencia a mejorar el ingreso al pasar del primer empleo al último es fuerte. Pero nada garantiza que la movilidad ocupacional sea un indicador fehaciente de mejora laboral y salarial. Al contrario, la degradación del trabajo se puede exacerbar con el tiempo por las políticas laborales orientadas a la flexibilidad salvaje y por la ineficacia de las políticas contra la pobreza.

En este contexto de pocas esperanzas para modificar las tendencias de la degradación del trabajo, cabe destacar que la retribución salarial es la principal preocupación de los jóvenes mexicanos (69\%), seguida de los servicios médicos y otras prestaciones (6.4\%). Lo anterior puede obedecer a diferentes razones que no se pueden aclarar por medio de la encuesta; sin embargo, se pueden hacer sugerencias como la influencia que puede tener el nivel de pobreza en el que vive la mayoría de la población, las exigencias de consumo y el hecho de ser autónomos a corta edad. De cualquier forma, el salario indigno que se les ofrece a los jóvenes mexicanos deriva de condiciones estructurales y de estrategias empresariales que poco se modificarán en un modelo de desarrollo neoliberal, en el que la precarización del empleo se ha convertido en una condición social: sólo el 11\% de los jóvenes cuenta con buenas remuneraciones y condiciones de trabajo no precarias (De Oliveira, 2006). 
Pese a la degradación del trabajo a que se ven sujetos, los jóvenes, en apariencia, no muestran una desafección al trabajo, el tiempo que dedican a sus actividades laborales es significativo; los jóvenes encuestados manifestaron que, en su último empleo, su dedicación semanal fue de la siguiente manera: un $5.2 \%$ trabajó más de sesenta horas, $64 \%$ le dedicó 40 horas o más y un $23.8 \%$ menos de treinta horas. Esta situación preocupa aún más en un medio laboral con salarios castigados que, sin embargo, supone jornadas completas de trabajo compatibles con los estudios.

La tendencia anterior que cuestiona las tesis de un rechazo de los jóvenes al trabajo se refuerza cuando se observa que los niveles de rotación laboral son poco preocupantes, pues recordemos que ésta se encuentra asociada a la desafección al trabajo. Los jóvenes, de acuerdo con la encuesta, se caracterizan por cambiar poco de un empleo a otro; el $73 \%$ de los jóvenes encuestados ha tenido entre uno y tres empleos, el 19.2 $\%$ entre cuatro y seis, el $3.9 \%$ entre siete y nueve y el $3.1 \%$ entre diez y más. A diferencia de los adultos, en los jóvenes tal rotación laboral estálejos de asociarse con una cuestión de seguridad y estabilidad laboral, tal vez la lógica radica en que muchos deciden quedarse en empleos mal pagados, antes que sufrir el desempleo total.

La continuidad en el empleo de los jóvenes, de acuerdo con los datos de la encuesta, puede estar relacionada con una actitud de resignación laboral en un contexto restringido de empleo. Aunque también puede ocurrir que les parezca poco atractivo cambiar de empleos si las características son similares entre los que tienen y los que se les ofrecen.

Los jóvenes mexicanos no se dan el lijo de mantenerse largo tiempo sin trabajar. Son trabajadores que buscan retener sus empleos y perdurar en ellos, pues caer en el desempleo los ha llevado a largas temporadas sin trabajo: la encuesta referida informa que los jóvenes que han estado sin trabajo entre uno y dos años son un $55.7 \%$ y los que rebasan dos años llegan a $14.3 \%$.
Sin embargo, trabajar desde temprana edad y buscar mantenerse en los empleos, como un sedimento social de la vida de un joven, no conduce a ninguna parte, pues el mínimo derecho a tener una vida digna se ha diluido, así como la posibilidad de construir una carrera laboral, por ello vale la pena preguntarse si el trabajo continúa como referente básico de las identidades de los jóvenes.

Los jóvenes mexicanos tienden al trabajo, aunque la situación de los empleos que encuentran es de baja calidad, la precarización laboral es el elemento distintivo: más de la mitad de jóvenes entre 15 y 29 años, y una tercera parte del grupo de 20 a 24 años, tiene contrato verbal; además, una tercera parte de cada grupo no tiene claridad respecto de su condición contractual. Por otro lado, las prestaciones son casi inexistentes: el $30 \%$ cuenta con aguinaldo, vacaciones y algún seguro médico público, pero sólo menos del $8 \%$ alcanza reparto de utilidades y crédito para vivienda; el $47.3 \%$ tiene salario base pero el $37 \%$ no cuenta con ninguna prestación social. Estos datos muestran la existencia de un mundo laboral no regulado, flexible y unilateral en donde los mínimos derechos del trabajador parecen concebirse como obstáculos al buen funcionamiento de la economía de mercado (De la Garza, 2006).

Los jóvenes mexicanos que logran insertarse en un empleo viven en la incertidumbre y en la inseguridad laboral. Ellos llegaron tarde a los empleos caracterizados como típicos de la era de oro del capitalismo: trabajos estables y de tiempo completo que garantizaban seguridad ocupacional y la construcción de un proyecto personal y familiar. Situación que tal vez ya no se presentará más debido a la aceptación, implementación y desarrollo de las políticas neoliberales del gobierno actual y, con toda seguridad, del futuro gobierno que seguirá con la custodia del legado de su antecesor.

Desde este tipo de situación de degradación laboral y social, que parece ser compartida por franjas 
de población significativas en América Latina, Tokman (1997) deriva repercusiones importantes como niveles altos de delincuencia y drogadicción que se han convertido por desgracia en los aspectos de mayor atención en la opinión pública. De esta condición sociolaboral poco favorable para los jóvenes, deduce dicho autor la falta de motivación y la ausencia de identificación con los valores sociales y políticos. En consecuencia, para los jóvenes el empleo precario conduce a la erosión de la integración social y al debilitamiento de una construcción ciudadana.

Esta situación permite a los empresarios la contratación temporal como una vía que les facilita elegir a los trabajadores que requieran en cada momento, lo cual va en detrimento de la población juvenil.

La precariedad de las relaciones y condiciones laborales va aparejada con la vulnerabilidad social de sectores cada vez más extensos. La situación de los jóvenes, como se vio, está más expuesta a condiciones laborales extremadamente precarias. La mayoría de los empleos, al ser precarios, incide en el crecimiento de la informalidad con bajas remuneraciones, poca seguridad y escasa productividad. Toda esta problemática de privación económica, derivada de las restricciones impuestas por la dinámica de los mercados de trabajo, se agudiza y genera la dificultad de incorporar al sistema productivo a los jóvenes (De Oliveira, 2006).

\section{Posiciones de los jóvenes mexicanos frente al trabajo}

La tesis de que los jóvenes europeos rechazan el trabajo es un asunto en discusión teórica y empírica, cuestión que nos sugiere mesura en la aplicación de discursos posmodernos o apocalípticos, procedentes de la sociedad industrial, en nuestro país, en virtud de las condiciones laborales y productivas específicas que vivimos. Asimismo, la idea de que el trabajo como referente de la identidad es y no es, o simultáneamente es las dos cosas, requiere información empírica, pues si usamos la teoría en términos especulativos puede ser orientada hacia donde se quiera sin el menor pudor de constatación.

En el caso mexicano hay un gran ayuno de estudios que analicen la relación entre jóvenes, trabajo y subjetividad, y los pocos que se encuentran suponen que el trabajo es un referente de interés, entre otros, en la conformación de la identidad, digamos que es y no es (Suárez Zozaya, 2004; Pérez Islas, 2001). Aquí es pertinente recordar la pregunta que se hace Sanchís, para Europa, respecto a qué tipo de jóvenes nos estamos refiriendo: ¿a los jóvenes del estado de bienestar que presuntamente estuvieron impregnados de la centralidad del trabajo? Si es así, vale interrogarse qué información se posee para demostrar tal tesis. Ahora, si se quiere obviar esa pregunta al menos se tendría que constatar que la sociedad mexicana en estos momentos está definida por los modelos productivos que prevalecen en los países centrales y que el trabajo atípico que tenemos es novedoso y similar a aquellos países, lo que es difícil de demostrar y constatar de modo contundente.

Parecen apresuradas las tesis que presumen que en el país el trabajo industrial tiende a desaparecer y con ello el trabajador industrial. Suárez Zozaya supone que la flexibilidad es la marca inevitable de la estructura productiva en el país, lo que traerá la muerte del trabajador y la extinción de sus derechos vinculados al trabajo. En un mundo de pobreza y de desempleo, los jóvenes le dan al trabajo un "sentido de utilidad lucrativa que aunado a los ingresos bajos que gana[n] les causa frustración, situación que confronta y erosiona la referencia al trabajo como sentido de vida" (Suárez Zozaya, 2004: 76). Para la mencionada autora, pensar que el joven tiene como única fuente de identidad el trabajo es un error; al contrario, propone la fórmula siguiente: "soy joven, soy mexicano (pobre); luego tengo que trabajar". 
En la actualidad es difícil suponer que la identidad se arma respecto a un solo lugar, como dicen Dubet y Martuceli, pero este presupuesto nos deja en un abandono muy fuerte pues todo lo que se le presenta al sujeto es susceptible de ser parte en la conformación de la subjetividad. Al menos en los discursos de la sociedad capitalista, en los que el trabajo tiene una fuerte importancia en las relaciones sociales, éstos tenían un fuerte referente de sociedad, lo que contrasta con los nuevos discursos que están completamente desdibujados de esta imagen e introducen un escenario en donde todo se vale en un conjunto de relaciones sociales vinculadas al trabajo.

En cuanto a lo que ocurre en México, es necesario demostrar primero que estamos en una sociedad en la que, si bien hay flexibilidad, también hay otras formas de producción. Por otro lado, es necesario dudar de la suposición de que por la pobreza y los bajos salarios que enfrentan, los jóvenes borran toda dimensión expresiva del trabajo y por consiguiente se conforma una visión utilitaria. Al contrario, ambas condiciones subjetivas no necesariamente tienen que verse como un continum y se pueden encontrar entrelazadas.

Resulta problemático sostener que en el modelo de sustitución de importaciones, pese a todas sus bondades en el espacio del trabajo, se conformara a un actor juvenil permeable y adherible - sin contradicciones, rechazos y conflictos-a una ética e ideología industrial. Tal como si las condiciones objetivas del trabajo en ese momento se transmitieran como reflejo hacia los valores, las actitudes, las racionalidades y la cultura de los jóvenes.

En contraposición, se puede pensar que al entrar en crisis ese modelo de desarrollo y al aparecer otro denominado neoliberal, entonces, como deducción lógica, también se estaría modificando la subjetividad del trabajo juvenil. También se puede presuponer que en esta nueva época económica, deberían aparecer actores laborales inconformes, tal vez indiferentes, quizás resignados o frustrados que rechazan la dimensión expresiva del trabajo.

Es muy funcionalista la dicotomía: MODELO DE SUSTITUCIÓN DE IMPORTACIONES = ACEPTACIÓN DE LA ÉTICA E IDEOLOGÍA DEL TRABAJO industrial VS MODELO NEOLIBERAL = RECHAZO DEL TRABAJO ASALARIADO INDUSTRIAL. Dicho de otra forma: ESTADO DE BIENESTAR = ÉPOCA DE ORO VS NEOLIBERALISMO= DESTRUCCIÓN.

También puede ser, como alargamiento analítico: ESTADO DE BIENESTAR = JÓVENES CON CENTRALIDAD EN EL TRABAJO VS NEOLIBERALISMO = JÓVENES CON RECHAZO AL TRABAJO

Los datos duros relacionados con las condiciones estructurales del trabajo pueden compararse entre ambos modelos del desarrollo capitalista, pero sería delicado tratar de hacer lo mismo con la subjetividad de los actores laborales y aún más cuando no se cuenta con información adecuada para ello, lo que nos llevaría a la realización de puras deducciones lógicas. En consecuencia, nos limitaremos a utilizar, para reconstruir esta parte del documento, los resultados de la encuesta de jóvenes (ENJ, 2001).

Son innegables los efectos negativos del neoliberalismo económico hacia una parte significativa de la población mexicana. Es un error suponer que ante tal situación de degradación del trabajo y de las condiciones de vida tendrían que aparecer actores sociales homogéneos en el rechazo hacia ese modelo: molestos, enojados, indiferentes, quizás frustrados. Pero más bien, hay una suerte de heterogeneidad de la acción social donde se entrecruzan actores que rechazan, otros que aceptan, como algo natural, y unos más, quizás, indiferentes a la degradación del trabajo.

Como se mencionó, Suárez Zozaya elabora una imagen de un joven frustrado hijo de la flexibilidad, tal 
vez como dato distintivo en comparación con el pasado proteccionista, que es difícil de sustentar con datos que ofrece la mencionada encuesta, también utilizados por la autora. Según datos de la encuesta, los jóvenes mexicanos son muy felices $(69.6 \%)$, poco felices $(25.4 \%)$ y nada felices $(1.7 \%)$. Estos datos sugieren mesura hacia la tentación de derivar actitudes, prácticas y acciones de rechazo y frustración hacia el trabajo derivadas mecánicamente de la situación económica y laboral degradante en la que vivimos los mexicanos.

Dicha apreciación se refuerza cuando se encuentran más jóvenes con satisfacción en su nivel socioeconómico que inconformes. Cinco de cada diez jóvenes aceptan que su situación económica es regular, pero tres más la definen como buena. La perspectiva pesimista no es posible establecerla desde este tipo de datos de encuesta, más bien parece que lo contrario es más posible. Sin embargo, sería arriesgado asociar que la felicidad de los jóvenes se liga sólo a su satisfacción económica. Hay otros espacios, y quizás de mayor peso, que pueden ser motivo de la alegría juvenil, como la sexualidad y la cultura, que se encuentran en transformación. Es claro que el joven mexicano, como ningún otro actor social, no es un homo economicus pero llama la atención la representación que hace de su situación socioeconómica en un país con graves carencias en ese nivel de realidad, por lo que resulta necesario preguntarse: ¿estamos ante un joven conservador que acepta su condición social deteriorada en espera de llegar a su vida adulta, en la que se piensa que se puede revertir tal situación?, o ¿también se puede pensar en un joven resignado a un presunto destino social inevitable?

Los jóvenes mexicanos se encuentran envueltos en la lógica peculiar de la sociedad del trabajo. Como dice Meda, las soluciones de la sociedad del trabajo se piensan en la misma lógica social, por ejemplo, la solución al desempleo se busca en la creación de más empleos, pero no en una visión diferente. Con base en este razonamiento los jóvenes mexicanos, pese a estar en una condición laboral de degradación, ven en ella misma las posibilidades de solución; ocho de cada diez jóvenes dicen estar satisfechos laboralmente (ENJ, 2001).

Este dato de la encuesta va contra toda lógica de la desafección al trabajo. Ahora bien, el concepto de satisfacción puede tener diversos sentidos que tampoco se aclaran en la encuesta. Se puede suponer que se está satisfecho con base en una actitud conformista que conduce a aceptar lo que se tiene, por ejemplo un empleo, en comparación con la probabilidad de estar peor si la satisfacción en ese contexto no se cumple. También la satisfacción puede ligarse a las condiciones de trabajo o a la forma de organización del trabajo. Es un dato bastante general que puede incluir diversas explicaciones, aun con su falta de precisión puede ayudar a problematizar imaginarios laborales de rechazo al trabajo adjudicados a los jóvenes.

$\mathrm{Al}$ contrario de lo que se puede esperar en un contexto de degradación laboral, los jóvenes además de estar satisfechos con su condición socioeconómica también dicen estar, como ya lo señalamos, a gusto con su trabajo.

Esta apreciación que en apariencia es contradictoria con la situación laboral pésima y degradante en la que se desenvuelven, puede verse aclarada si se revisa lo que a los jóvenes les gusta de sus trabajos: su empleo les posibilita aprender (22.8\%); estar en un buen ambiente laboral (17.6\%); adquirir experiencia (16\%) tener un salario $(12.9 \%)$, entre otros aspectos menos relevantes estadísticamente. Aprender, un buen ambiente y lograr experiencia se relacionan con una visión de realización personal de los jóvenes muy alejada de razones instrumentales como la determinación del salario.

No hay que perder de vista que los jóvenes tienen más presencia en actividades laborales ubicadas en el sector servicios y caracterizadas por bajos niveles tecnológicos y puestos de trabajo descalificados. De esta ubicación ocupacional sería improcedente imputarles a los jóvenes un rechazo sin más al trabajo 
industrial. Se podría asumir que sus preferencias laborales se inclinarán hacia los servicios con base en un cálculo racional en la desafección al trabajo industrial, posición en la que los jóvenes serían los culpables de no tener empleo, o que independientemente de su subjetividad ellos son clasificados y seleccionados para la conformación de un mercado de trabajo a priori con las exigencias económicas neoliberales del país, imagen que condena a los jóvenes a la inacción política.

En parte se puede suponer que a los jóvenes les parece poco atractivo emplearse en una fábrica, pero también hay que observar que en el sector industrial cada vez se dificulta más generar empleos.

Es muy probable que parte importante de la población juvenil continúe incorporándose al comercio, sobre todo en su parte informal. Tal vez se achique su movilidad ocupacional vertical y tal vez se mantenga su reproducción horizontal en la economía sumergida. Los niveles de baja tecnificación y calificación no son constelaciones cerradas para sustentar ideológicamente que ahí el aprendizaje y la experiencia serían poco significativos. Puede ser que los jóvenes perciban que a su edad cualquier trabajo ofrece posibilidades de aprendizaje y experiencia que le ayudarán en el futuro. Lo contrario sería suponer que lo más valioso y necesario es el trabajo industrial y fuera de ese mundo todo sería anormal. Hay que romper con el prejuicio de presentar el trabajo industrial como el modelo a seguir o el referente necesario de comparación con metas laborales exitosas. Los servicios tienen su propia lógica y estética por lo que sería aventurado suponer que las calificaciones en ese sector tienen menor valor social que las de la industria. Como es un sector bastante heterogéneo habría que ubicar qué tipo de ocupaciones se están observando.

La asociación de jóvenes con niveles de calificación bajos versus adultos con altas calificaciones tampoco es adecuada. Al contrario, se puede estimar que los jóvenes tienen una visión positiva de sus calificaciones cuando ésta se asocia a las dimensiones expresivas del trabajo: el aprendizaje, la experiencia y el ambiente laboral. Desde aquí sería inadecuado pasar a la apreciación de que los jóvenes estén pensando mantenerse en esas actividades para siempre, tal vez algunos las conviertan en un estilo de vida u otros intenten una movilidad intra sectores o sólo al interior de los servicios, en todo caso falta información para observar esos movimientos laborales de la juventud.

Con la información expuesta de la encuesta se ha argumentado a favor de que los jóvenes se sienten identificados con su trabajo, aun así no dejan de ser críticos respecto a ciertos aspectos de sus empleos. Una parte significativa de los encuestados (33\%) señaló que lo que más le disgusta de su empleo es su salario. En orden jerárquico sigue el tiempo para estar con su familia y sus limitaciones para ascender, entre otros aspectos de disgusto muy menores.

La relación salarial mantiene un estatus en la conformación de los valores y actitudes de los jóvenes en el mundo laboral. Los jóvenes aceptan empleos con limitada tecnificación y bajas calificaciones, pero cuestionan la asignación de un salario bajo.

En la lógica empresarial, actividades económicas con bajos niveles tecnológicos y de calificación se compaginan con salarios deprimentes. Por ello, se contradicen con la perspectiva juvenil, en la medida en que los jóvenes guardan una significativa estima por el trabajo, pero critican y rechazan los empleos que ofrecen un salario degradante. De manera que los jóvenes, a través de su experiencia laboral, constituyen un conocimiento práctico que orienta a la desmitificación de los empleos precarios.

Los jóvenes mexicanos no cuestionan el trabajo, más bien, es la relación salarial como vinculación social la que se encuentra en el banquillo de los acusados. Los jóvenes asocian a su trabajo aspectos de la dimensión expresiva y objetan el salario como una característica de disgusto que desean transformar hacia una orientación expresiva, por ello aspiran a un empleo en 
el que se gane un buen salario (69\%), que ofrezca prestaciones sociales $(6.4 \%)$ y que permita estudiar (4.4\%), entre las ambiciones más relevantes, tal como se observa en los resultados de la encuesta nacional, que hemos venido refiriendo.

Los jóvenes rechazan los empleos que se sustentan en la degradación salarial. Se encuentran en la búsqueda de un nuevo sentido laboral, pero éste se relaciona con el salario del que depende su capacidad de relacionarse con los otros actores sociales en la reproducción y en el consumo.

Desde esta postura crítica y desmitificadora del uso capitalista del salario, que se combina con otros campos de su reproducción social, los jóvenes forjan sus posiciones hacia las instituciones de regulación laboral. Es sintomático que en los jóvenes encuestados las tres instituciones que mayor confianza tienen para ellos son la familia, la escuela y la iglesia. Su contraparte se encuentra en el congreso legislativo, los partidos políticos y sindicatos.

Los jóvenes mexicanos se sienten poco identificados con las organizaciones sindicales e inclusive se puede pensar que aquellos que estén incorporados a este tipo de asociaciones tampoco encontrarán en ellas un motivo de orgullo y adhesión voluntaria; no sólo hay abismos culturales para entender a los sindicatos, también las limitaciones políticas y el autismo social que padecen, derivan en que sean extraños para los jóvenes.

Inclusive, puede pensarse que la evaluación de los sindicatos se realiza a partir de la identificación de esa institución con los líderes sindicales. De los jóvenes encuestados, un $49.5 \%$ no confía en ellos, $35 \%$ confía poco y sólo un $12.1 \%$ se identifica con ellos. Poco sorprendente resulta que los jóvenes confíen más en los empresarios (16.8\%), que en los líderes sindicales (12.1\%), que se encuentran en un nivel de aceptación similar que el de los judiciales.

En el futuro, las organizaciones sindicales verán agravados sus problemas de afiliación sindical al mantener sus prácticas corporativas y por las transformaciones del mercado de trabajo. El alejamiento de los jóvenes de las organizaciones sindicales puede considerarse como una posición enclavada en la brecha generacional o también puede interpretarse como una institución que ha fracasado en la regulación salarial, con líderes sindicales que por sus prácticas de relajación, dadas a conocer con amplitud por los medios de comunicación masiva, se han ganado el rechazo de la población joven.

Así pues, los jóvenes son un sujeto reflexivo que se identifica con el trabajo como realización humana, pero critica y desmitifica los empleos de bajos salarios, así como las instituciones que presuntamente defienden los derechos del trabajador. Más que ser un actor pragmático en su totalidad y orientado por una racionalidad instrumental exclusiva, el joven considera el trabajo como valor personal y social sobre el que aún puede sostener aspiraciones y proyectos de vida.

De estas observaciones tampoco puede desprenderse que el trabajo sea la cuestión exclusiva que explique la construcción de la vida de los jóvenes. Es obvio que existen otros espacios de la vida de los jóvenes como el consumo cultural y la familia, por mencionar algunos, que son tan importantes como el trabajo en la constitución de un sujeto llamado joven. Los jóvenes mexicanos aspiran a ser alguien y algo en sus vidas. En la constitución de su ser joven y su proyección en ser adulto, el trabajo forma parte de sus necesidades y de sus visiones de futuro.

Desde nuestra perspectiva, la concepción de un joven bajo la lupa de una reconfiguración total de su identidad, orientado por un pragmatismo hacia el trabajo, no tiene semejanzas, al menos, con los datos de la encuesta mencionada.

En cambio, los jóvenes mexicanos sí parecen preocupados por su futuro; el $46.9 \%$ manifestó que su futuro es importante en contraposición con $32.2 \%$, que indicó que es más importante su presente (ENJ, 2001). 
Tal vez la diferencia no sea abismal, pero al menos ayuda a problematizar la idea que se elabora desde el mundo adulto de un joven desmadrozo, poco responsable y no comprometido, cuyo futuro desaparece de sus perspectivas ya sea por una cultura hedonista o por la desesperanza hacia el modelo económico actual.

Al contrario, de acuerdo con la encuesta que comentamos, los jóvenes están en desacuerdo en un $48.4 \%$ en la propia imagen que muchos jóvenes labran de sí mismos como apáticos y desinteresados. Sin embargo, hay otro $27.8 \%$ que estuvo de acuerdo con esa percepción de auto evaluación.

Esta evaluación de sí mismos los coloca en una posición optimista en comparación con las imágenes que tienen de las generaciones de los trabajadores del pasado. Los jóvenes del presente sienten que están en mejor posición (48.1\%) que sus padres en cuanto a la posibilidad de encontrar empleo; sin embargo, hay una porción menor que indica que está peor (18.3\%), mientras que el $30.9 \%$ considera que está igual que como estuvieron sus padres. Esa tendencia de optimismo tiende a decrecer en cuanto la comparación se realiza con los ingresos. El 42.0\% considera que obtendrá mejores ingresos que sus padres. Pero el $33.7 \%$ se sitúa en la misma condición de igualdad, en contra de los pesimistas que son el $21.8 \%$. Con esta información por lo menos contamos con un dato de comparación entre los jóvenes de hoy y los de antes, por lo cual, se dificulta asociar lo expresivo a las generaciones pasadas y lo instrumental a los nuevos jóvenes.

Se reitera la imagen que ya se había destacado: el problema de los jóvenes es el de los salarios y en menor medida el del empleo. Por ello, tal vez cuando se les pregunta respecto a los problemas más graves del país destaquen tres: la pobreza (60.4\%), el desempleo (11.7\%) y la corrupción (10.1\%). Es notoria la diferencia de la preocupación por la pobreza con las otras más cercanas. Puede considerarse que los jóvenes realizan sus propias articulaciones simbólicas de la realidad en la que salario, empleo y pobreza conforman una cadena que se elabora en términos de generar preocupación, inquietud y posiblemente incertidumbre. Desde esta base de datos empíricos se puede elaborar el presupuesto de que los jóvenes mexicanos reclaman mayor centralidad del salario en sus vidas, al igual que los adultos.

Más salario para enfrentar las condiciones deplorables personales y familiares en que vive la mayoría de la población mexicana no se contradice con actividades que se consideran propias de esa edad, como la diversión. Seis de cada diez jóvenes dicen divertirse mejor que sus padres. ¿Qué dirán los padres?, no lo sabemos.

Ser consumista y divertirse, en apariencia, no conforman una nueva centralidad en la identidad de los jóvenes mexicanos. Éstos se encuentran aún con fuerza definidos por las exigencias de una sociedad que se reproduce a partir de la lógica del mercado y de la maximización de la ganancia.

Para los jóvenes del país tener un empleo (27.2\%) es más importante que casarse (25.2\%); tendríamos que agregar que debería tratarse de un empleo con un buen salario. Las diferencias entre ambas percepciones son poco significativas, tal vez porque en el imaginario de los jóvenes empleo-salario y unión de pareja son articulaciones necesarias para ingresar al mundo de los adultos, en el que tener un empleo es definitivo para la construcción de un futuro.

Inclusive, tener empleo y un buen salario significa mayor peso en el imaginario laboral de los jóvenes que tener un negocio propio. Pueden ser muchas las razones que expliquen tal concepción, pero independientemente de ellas, las políticas del gobierno deberían revisar con cuidado sus opciones de autoempleo, que son las que se ofrecen para enfrentar el desempleo.

Con la utilización didáctica de la dicotomía racionalidad expresiva versus racionalidad instrumental tendríamos a un joven mexicano constituido por una racionalidad expresiva hacia el trabajo, que se articula con una racionalidad instrumental hacia el empleo y el salario, no como una 
forma de rechazo sino como un cuestionamiento para impregnarlos de una lógica expresiva. Más que demostrar tesis que explican el comportamiento del joven europeo, como el de la primacía de una racionalidad instrumental hacia el trabajo asalariado, es necesario problematizar el conocimiento teórico acumulado para entender los casos específicos de otros países como el nuestro, en el que se articulan la racionalidad expresiva y la instrumental para pensarlas como una dualidad y no como cuestiones separadas y opuestas.

Con lo que hemos trazado en estas líneas hemos pretendido abrir más el debate, es claro que no queda agotado, y a la vez establecer nuevas rutas de indagación bajo el supuesto de ampliar las capacidades o posibilidades de análisis de diversos conceptos criticables, pero torales para el estudio de relaciones sociales como las planteadas aquí. A la vez, hemos buscado enfrentar las opciones analíticas de las relaciones de los jóvenes mexicanos con el trabajo, que no dejan espacios y en cambio generan salidas interpretativas fáciles frente a una realidad social compleja.

\footnotetext{
Notas

${ }^{1}$ No obstante, podría decirse, para el caso mexicano, que los cambios en el modelo productivo han dado pie a cambios en la perspectiva de los jóvenes, como la de otros, sobre el trabajo. Esto no lleva como consecuencia su generalización. En todo caso, es necesario mayor análisis, pero a partir de estudios que se propongan especialmente esta reflexión y conlleven valoraciones de poblaciones juveniles. Justamente en lo que sigue veremos las pocas evidencias de la subjetividad juvenil mexicana sobre el trabajo.

${ }^{2}$ De acuerdo con la Encuesta Nacional de Empleo, la población ocupada en el año 2000, del total de la población, era de $39.28 \%$ y la desocupada abierta era de $0.66 \%$; para el 2001 fue de $38.68 \%$ y $0.68 \%$ respectivamente; para el 2002 ascendió al $39.11 \%$ y $0.76 \%$; en el 2003 la población ocupada tuvo un leve descenso, $38.99 \%$, mientras que la población desocupada fue de $0.85 \%$; por último, en el 2004 ambos aspectos se incrementaron al $40.16 \%$ y $1.04 \%$ respectivamente.
}

${ }^{3}$ El sector primario durante el período de 2000-2004 tuvo un retroceso en cuanto a la generación de empleo. La población que realizaba actividades agropecuarias en el 2000 era de 7, 129,529 y en el 2004 descendió a 6, 927,881; lo mismo ocurrió en la extracción de petróleo donde pasó de 90,552 a 73,821; en cambio la explotación de minas y canteras subió de 66,585 a 95,724. En el sector secundario, con excepción de refinación de petróleo, derivados y petroquímica básica (68,590 en 2000 y 77,970 en 2004) y la de productos alimenticios, bebidas y tabaco que pasó de 1,580,399 a 1,798,033, las demás ramas descendieron. Situación diferente aconteció en el terciario, las distintas ramas crecieron en general de manera constante y las que lo hicieron significativamente fueron la del comercio minoritario que ascendió de 5, 833,694 a 6, 970,723 y la de preparación de alimentos y bebidas en la vía pública y a domicilio de 530,195 a 767,355 (ENE, 2005).

${ }^{4}$ En el período 2000-2004 la participación femenina en la rama de productos alimenticios, bebidas y tabaco pasó de $660 \mathrm{mil}$ a 782 mil; en la industria del calzado tuvo un descenso importante de 123 mil a 85 mil; al igual que la población total, la presencia de la mujer en el sector terciario creció, el comercio minorista se incrementó de 2 millones 938 mil a 3 millones 623 mil y la preparación de alimentos en la vía pública pasó de 330 mil a 497 mil (enero 2005)

${ }^{5}$ El total de la población en desocupación abierta, en el trimestre de octubre-diciembre de 2004 es de 1,143,652 y el segmento de población de jóvenes de 12 a 29 años tiene un alto índice de desocupación al llegar al 63\% de la población desocupada.

\section{Bibliografía}

Accornero, A., 1980, Il lavoro come ideología, Bolonia, Il Mulino Blanch, J.M., 1986, Desempleo juvenil y salud psicosocial, Documentos de psicología, Universidad Autónoma de Barcelona, Barcelona.

Capechi, V., 1980, “Lavoro e condizione giovanile”, en Problema della transizione, núm.4.

Coriat, Benjamín, 1985, "Del sistema Taylor al taller en serie robotizado", en Revista Mexicana Ciencias Políticasy Sociales, núm 121, México.

Cottereau, A., 1979, “ 'Les jeunes contre le boulot: une historie vieille come le capitalismo”, Autremet, núm 21, París.

Cuvillier, R., 1974, "El trabajo y los trabajadores ante las ideas y la práctica sociales”, Revista Internacional del Trabajo, vol. 89. 
De Ibarrola, María, 2001, 'Los cambios estructurales y las políticas de capacitación y formación para el trabajo en México: Un análisis de la expresión local de políticas nacionales", en Pieck, E. (coord), Los jóvenes y el trabajo. La educación frente a la exclusión social, CINTERFOR/OIT, Instituto Mexicano de la Juventud, México.

De la Garza Toledo, Enrique (coord.), 1998, Modelos de industrialización en México, UAM-I, México.

De la Garza Toledo, Enrique, 2000, "Fin del trabajo o Trabajo sin fin", en Enrique de la Garza (coord.), Tratado Latinoamericano de Sociología del Trabajo UAMI-COLMEX- FCE, México.

De la Garza Toledo, Enrique, 2006, "Balance laboral y sindical del gobierno de Vicente de Fox", ponencia presentada en el V Congreso Nacional de la AMET, Trabajo y reestructuración: los retos del nuevo siglo, del 17 al 19 de mayo, Oaxtepec, Morelos.

De Medina Diez, R. 2000, Jóvenes y Empleo en los noventa, Cinterfor, Montevideo, pp. 49-94.

De Oliveira Barbosa, Orlandina, 2006, "Jóvenes y precariedad laboral en México", ponencia presentada en el V Congreso Nacional de la AMET, Trabajo y reestructuración: los retos del nuevo siglo, del 17 al 19 de mayo, Oaxtepec, Morelos.

Dubet, Francois y Danilo Martuceli, 1998, ¿En qué sociedad vivimos?, Losada, Buenos Aires.

Encuesta Nacional de Empleo Urbano (ENEU), 2000, Cifras durante 1995-2000, México.

Encuesta Nacional de Empleo Urbano (ENEU), 2000, INEGI, México.

Encuesta Nacional de la Juventud (ENJ), 2001, Instituto Nacional de la Juventud/INEGI, Noviembre 2001, México.

Friedmann, George, 1963, Tratado de Sociología del Trabajo, FCE, 2 volúmenes, México.

Galland, O., 1984, "Les jeunes”, en La Découverte, París.

García, Fernando M., 1984, "Situación laboral de la juventud española", vV AA, Informe sociológico sobre la juventud española 1960/82, Madrid, S.M.

Gorz, A., 1982, Adiós a proletariad, El viejo Topo, Barcelona. Gorz, A.,1995, La metamorfosis del trabajo, Ed. Sistema, Madrid.

Harrybey, Jean Marie, 2001, "El fin del trabajo: de la ilusión al objetivo”, en De la Garza, Enrique, Julio Nefffa C. (coord), El futuro del trabajo- El trabajo del futuro, Clacso, Buenos Aires.

Hayman, R., 1996, "Los sindicatos y la desarticulación de la clase obrera”, en Revista Latinoamericana de Estudios del Trabajo.

Leyva Piña, Marco A. y Javier Rodríguez Lagunas, 2000, “La globalización y la Sociología del Trabajo”, en Hermenéutica y filosofía. Revista Iztapalapa, julio-diciembre, año 20, núm 49, México.

Llamas Huitrón, Ignacio, 1993, “Gastos en Educación e Incorporación al Mercado de Trabajo de los Jóvenes de los Hogares Pobres de México", en Análisis económico, vol. XI, núm. 22, México.

Méda, Dominique, 1998, El trabajo: Un valor en peligro de extinción, Ed. Gedisa, Barcelona.

Miranda López, Francisco, 2002, "Transición educaciónmercado de trabajo en jóvenes", en Jóvenes mexicanos del siglo XX. Encuesta nacional de la Juventud 2000, IMJ, México.

Moncada, A., 1979, La adolescencia forzosa, Dopesa, Barcelona. Navarrete López, E. Liliana, 2006, “Ante la permanencia escolar y el trabajo. Ventajas y desventajas”, ponencia presentada en el V Congreso Nacional de la АмEт, Trabajo y reestructuración: los retos del nuevo siglo, del 17 al 19 de mayo, Oaxtepec, Morelos.

Navarro, Vicenç, 2002, Bienestarinsuficiente, democracia incompleta. Sobre lo que no se habla en nuestro país, Anagrama, Madrid.

Neffa, Julio César, 2004, Presentación del debate reciente sobre el fin del trabajo, www.plataforma.uchile.cl/fg/semestre2/-2004.

OCDE, 1984, "Naturaleza de las diferencias entre paro juvenil y paro adulto", en De juventud, núm. 85.

Offe, Claus, 1992, La sociedad del trabajo: Problemas estructurales y perspectivas de futuro, Alianza, Madrid.

Pérez Islas, José Antonio y Maritza Urteaga, 2001, “Los nuevos guerreros del mercado. Trayectorias laborales de jóvenes buscadores de empleo", en Pieck, E. (coord), Los jóvenes y el trabajo. La educación frente a la exclusión social, UIA-UNICEFCINTERFOR/OIT-RET-CONALEP, México. PREALC, 1992, "El empleo urbano: diagnostico y desafíos de los noventa", PREALC-Informa, abril, núm. 29.

Pries, Ludger, 1992, "El cambio industrial en las sociedades modernas como sociedades de riesgo", en Sociología del trabajo, núm 12, Madrid, pp. 59-82.

Prieto, Carlos, 1999, Trabajadores y condiciones de trabajo, Ediciones HOAC, Madrid.

Romagnoli, G., 1984, " Il lavoro e i suoi significati", en $V V$ AA. Giovani oggy, Il Mulino, Bolonia.

Salas Carlos y Eduardo Zepeda, 2003, "Empleo y salarios en el México contemporáneo”, en De la Garza, Enrique y Carlos Salas (coord.), La situación del trabajo en México 2003, UAM/ Plaza y Valdés, México, p.56.

Salvia, Agustín y Ana Miranda, 2000, "Los jóvenes y la exclusión en la década de los noventa", en Revista de 
estudios sobre Juventud. Nueva Época, julio-diciembre, año 4, núm. 12, pp. 58-71.

Sanchís, E., 1991, De la escuela al paro, Ed. Siglo XXI, Madrid. Schwartz, B., 1982, "La inserción profesional y social de los jóvenes", en Revista de Trabajo, núm. 66.

Standing, Guy, 2000, "La inseguridad laboral", en Revista Latinoamericana de Estudios del trabajo, año 6, núm.11, pp.47105, (Traducción del Cap. 6 de Standing (1999), Global Labour Flexibility. Seeking Distributuve Justice, Mac Millan Press, Londres.)

Suárez Zozaya, María Herlinda, 2004, "Jóvenes Mexicanos y Nuevo Capitalismo”, en Reguillo, Rossana, et al.,
Tiempo de Híbridos, Imj/Generalitat de Cataluña/ CIIMU, México.

Tokman, Víctor E., 1997, “El trabajo de los jóvenes en el post ajuste", en Jóvenes, formación y empleabilidad, Uruguay, Boletín Cinterfor OIT, abril-septiembre, pp. 139-140.

Vatin, Francoise, 2004, Trabajo, ciencias y sociedad: Ensayos de sociología y de epistemología del trabajo, Ed. Lumen, Buenos Aires, Valenzuela, Arce, 2001, Encuesta Nacional de juventud 2000, IMj, México.

Zapata, Francisco, 1993, "Crisis del sindicalismo en América Latina”, en Economía y trabajo, julio-diciembre, año 1, núm. 2. 